\title{
A material database for the computational assessment of the degradation of historical masonry
}

\author{
L. Fiala, J. Maděra, E. Vejmelková \& R. Černý \\ Department of Materials Engineering and Chemistry, \\ Faculty of Civil Engineering, Czech Technical University in Prague, \\ Czech Republic
}

\begin{abstract}
Numerical simulation of heat, moisture, salt and momentum transport is often applied for the investigation of building materials, nowadays. However, the results would not be satisfactory without credible and precise input data for the computations. Therefore, the results of laboratory experiments have to be stored and shared. In this paper, we focus on the material parameters of historical masonry in the manner of a system for their storing and utilization. To provide the data in a sufficient and safe way, make it accessible across the computer platforms and realize a connection between the experimental measurements, its circumstances and performers, a web-based database system is designed. It provides a solution to several issues: data backup and sharing, ensuring uniformity and serviceability on separate yet easy accessible storage. The database offers the descriptions, prescriptions, references and values of parameters of materials arranged in several categories. The online PHP application is based on the MVP concept with RMD-type MySQL database equipped by data conversion and interpretation tools. The contents of current version were measured and consolidated on the Department of Materials Engineering and Chemistry, Faculty of Civil Engineering, Czech Technical University in Prague. Several characteristic examples of the practical application of the database are presented, demonstrating its capability to act as an effective tool for the computational assessment of degradation of historical masonry Keywords: storage of experimental data, MVP architecture, RMD, SQL.
\end{abstract}




\section{Introduction}

Scientific research produces a large amount of important data, such as experimentally determined data, data obtained from monitoring systems or data obtained by complex calculations. Collected data are valuable due to the fact that their accumulation can be very time-consuming and that they can be used later in many ways, such as input data for simulation tools or as a data-mining analyses source. The need of a convenient data storage solution is present across the scientific fields [1-3], including materials engineering [4,5].

Regarding the materials engineering, these data are represented by measured materials parameters which are mostly of three groups: constants, functional dependencies on one variable and functional dependencies on two variables. Especially the second and the third case can produce a huge amount of data, due to the fact that measurements need to be repeated several times, in order to receive meaningful and representative results. Typical representatives of such a type of measurement which can produce thousands of pair values within one measurement are: assessment of the cumulative and the distribution pore size curve or time-monitoring of thermal properties such as the heat flux used for calculation of the thermal conductivity from the data collected in steady-state phase. It is evident that some robust data storage solution needs to be applied. Data storage system must be reliable due to the fact that data loss would be fatal and operation with data should be simple, preferably transparent to a user. Therefore, additional presentation and application layers need to be included in the software application.

This paper is dealing with the data storage/manipulation web-oriented application used by researchers from the Department of Materials Engineering and Chemistry, Faculty of Civil Engineering, CTU Prague. Database engine is based on MySQL (database layer), presentation and application layer on PHP5 and Nette framework. Data manipulation and data export to complementary computation systems and examples of practical utilization are presented with a focus on a usability for simulations of historical masonry heat and moisture transport.

\section{MVP concept of materials database}

In the past, a unified approach of a big amount of experimentally obtained data storage did not exist. The fundamental problem was in variety of formats, missing standardized safe data repository and therefore a problematic data workability by various software. Data were stored in files with user-defined structure and could be used just by one particular software. This approach led to a problematic reusability of data on different software platforms and the subsequent needs of data conversion. Therefore, the demand for a unified storage system appeared. SQL based database systems suit the need very precisely. It is a reliable, fast and time-proven solution. SQL databases are currently widely used as a data storage for the sake of a good data structure organization, easy accessibility and connectivity with web applications. 
Database layer has to be supplemented by additional layers to reach a comfort and easy-to-use software. In practice, three layered systems: Model-View-Presenter (MVP) and Model-View-Controller (MVC), are used. Figure 1 describes a typical communication flows between three layers within MVP architecture.

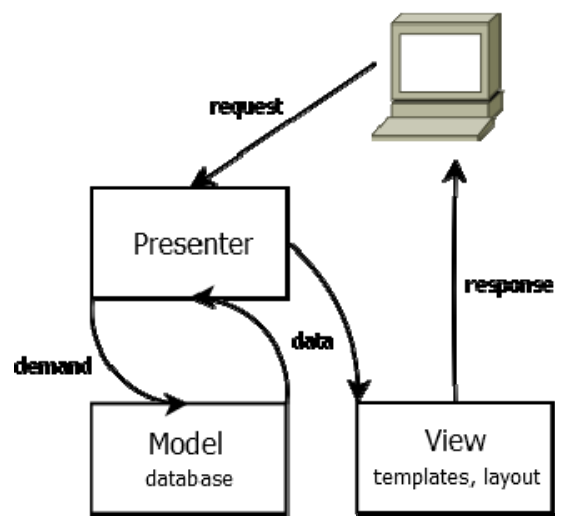

Figure 1: MVP architecture.

The database layer is represented by Models, templates in a form of web pages and web forms by Views. Presenters include a program code operating with data obtained from Model, calculating results, preparing the data for a graphical presentation and preparing the final data for the View templates that are presented to the user.

\section{Data structure and manipulation}

The materials database, hosted on servers of the Department of Materials Engineering and Chemistry (Figures 2-3), is based on Nette platform. Nette is one of a wide range of MVP frameworks that extends a widely used PHP5 programming language. Both, Nette and PHP5 are open source solutions. Database layer is presented by an open source MySQL as a reliable time-proven SQL database engine.

Data within MySQL (generally SQL database) are organized in a form of tables. Each table consists of atomic attributes with defined data type. Data (rows) are identified by primary keys. Two or more tables can be interconnected via primary keys. Basic DM (data manipulation) is implemented by SELECT, INSERT, UPDATE, DELETE commands.

The materials database can be accessed by three user roles: administrator, user and visitor. Administrator grants access to the users, approves measurements and adds comments to measurements. User adds and edits materials and measurements and comments measurements of other users. The visitor can manipulate with just a limited number of materials in read-only 
regime. Two language mutations (English and $\mathrm{Czech}$ ) are available for a more comfortable operation with the database.

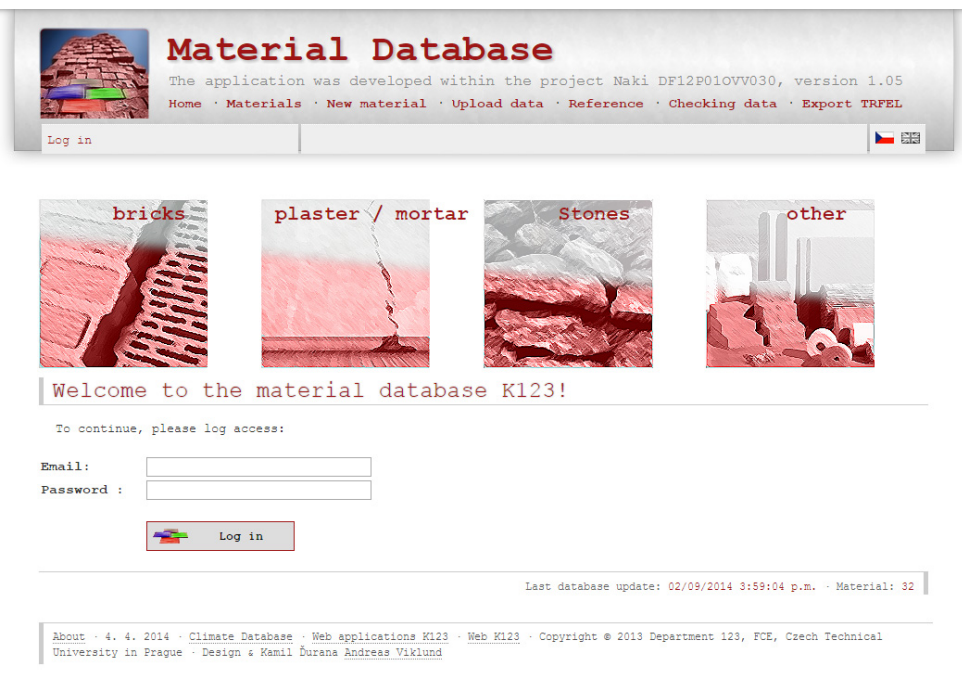

Figure 2: Materials database front end.

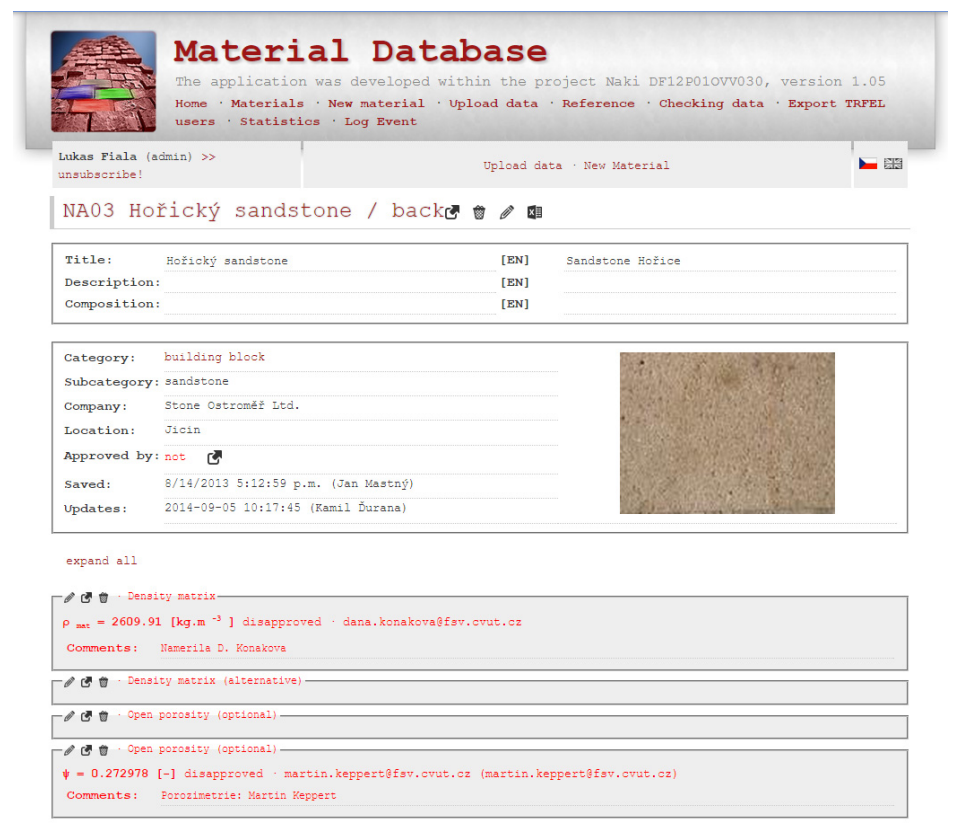

Figure 3: Material information. 
Database consists of twelve SQL tables maintaining information about users, references, material categories, quantities, statistics, etc. The crucial information regarding the measurements are stored in data table data and measurement, which are connected with other table, such as category, user and quantity. Each material is described in the table material. Materials are identified by the primary key id_material and belong to a given category/subcategory, such as historical stone, historical plaster, brick or insulating material. In the material table, basic information, such as name, description, prescription or a material producer are described. In addition, taken images of materials are stored. The quantity table comprises observed properties identified by the id_quantity key. It keeps information about name, unit, quantity and accompanying information represented by flags, such as the fact whether the property value is constant or a function dependent on another parameter. Information about experiments are stored in two tables: measurement and data. The measurement table identifies the measured material by the id_material key and provides information about the person who measured the given property (measured_by), about the date when the measurement was added to the database (datetime) and about the measurement approval (approved_by). In Figure 4, the structure of the measurement table is presented.

$\begin{array}{rlll}\mathbf{1} & \text { id_measurement } & \text { BIGINT } & \mathbf{1 0 0} \\ 2 & \text { id_material } & \text { BIGINT } & 100 \\ 3 & \text { id_qx } & \text { BIGINT } & 100 \\ 4 & \text { id_qy } & \text { BIGINT } & 100 \\ 5 & \text { id_qz } & \text { BIGINT } & 100 \\ 6 & \text { dimension } & \text { TINYINT } & 1 \\ 7 & \text { is_approved } & \text { TINYINT } & 1 \\ 8 & \text { is_primary } & \text { INT } & 1 \\ 9 & \text { comment } & \text { VARCHAR } & 1000 \\ 10 & \text { datetime } & \text { DATETIME } & \\ 11 & \text { downs } & \text { BIGINT } & 100 \\ 12 & \text { saved_by } & \text { BIGINT } & 100 \\ 13 & \text { deleted_by } & \text { BIGINT } & 100 \\ 14 & \text { approved_by } & \text { BIGINT } & 100 \\ 15 & \text { deleted } & \text { TINYINT } & 1 \\ 16 & \text { qtype } & \text { VARCHAR } & 100 \\ 17 & \text { measured_by } & \text { VARCHAR } & 250 \\ 18 & \text { processed_by } & \text { VARCHAR } & 250\end{array}$

Figure 4: $\quad$ Structure of measurement table.

A snippet of measured data stored in data SQL table is shown in Figure 5. 


\begin{tabular}{|r|r|r|r|r|}
\hline id_data & id_measurement & value_x & value_y & value_z \\
\hline $\mathbf{3 8}$ & 16 & 0.743809 & 1.73 & 0 \\
\hline $\mathbf{3 9}$ & 16 & 1.00694 & 1.79667 & 0 \\
\hline $\mathbf{4 0}$ & 17 & 0 & 649.787 & 0 \\
\hline $\mathbf{4 1}$ & 17 & 0.743809 & 661.483 & 0 \\
\hline $\mathbf{4 2}$ & 17 & 1.00694 & 665.604 & 0 \\
\hline $\mathbf{4 3}$ & 18 & 0 & 3.29167 & 0 \\
\hline $\mathbf{4 4}$ & 18 & 0.00743809 & 3.31167 & 0 \\
\hline $\mathbf{4 5}$ & 18 & 0.0100694 & 3.60333 & 0 \\
\hline $\mathbf{4 6}$ & 19 & 2609.91 & 0 & 0 \\
\hline $\mathbf{4 7}$ & 20 & 1994.31 & 0 & 0 \\
\hline $\mathbf{4 8}$ & 21 & 0.235882 & 0 & 0 \\
\hline $\mathbf{4 9}$ & 22 & 0 & 17.1 & 0 \\
\hline $\mathbf{5 0}$ & 22 & 27.5 & 17.1 & 0 \\
\hline $\mathbf{5 1}$ & 22 & 73.5 & 2.6 & 0 \\
\hline $\mathbf{5 3}$ & 22 & 100 & 2.6 & 0 \\
\hline $\mathbf{5 4}$ & 23 & 0 & 1.42 & 0 \\
\hline $\mathbf{5 5}$ & 23 & 0.630539 & 1.44 & 0 \\
\hline $\mathbf{5 6}$ & 23 & 4.58832 & 1.654 & 0 \\
\hline $\mathbf{5 7}$ & 23 & 9.13848 & 1.725 & 0 \\
\hline $\mathbf{5 8}$ & 23 & 12.8913 & 1.86646 & 0 \\
\hline $\mathbf{5 9}$ & 23 & 16.8946 & 1.92667 & 0 \\
\hline $\mathbf{6 0}$ & 24 & 0 & 712.026 & 0 \\
\hline $\mathbf{6 1}$ & 24 & 0.630539 & 725.2 & 0 \\
\hline $\mathbf{6 2}$ & 24 & 4.58832 & 806.032 & 0 \\
\hline $\mathbf{6 3}$ & 24 & 9.13848 & 895.173 & 0 \\
\hline $\mathbf{6 5}$ & 24 & 12.8913 & 965.818 & 0 \\
\hline & & 16.8946 & 1038.48 & 0 \\
\hline & 24 & 0 & 2.575 & 0 \\
\hline
\end{tabular}

Figure 5: Snippet of data table content.

\section{Data export}

Formerly, a robust external computation tool used for simulation of heat transport and accumulation, was developed at the Department of Mechanical Engineering, Faculty of Civil Engineering, CTU Prague. Due to the fact that simulations with experimentally determined material data are in our scope of interest, data from materials database can be exported into three types of format that is simulation tool able to import and use for calculations. It is possible to prepare input data for simulation of up to ten different materials layers placed between the interior and exterior conditions. Figure 6 presents the template used for export administration with four chosen layers. 


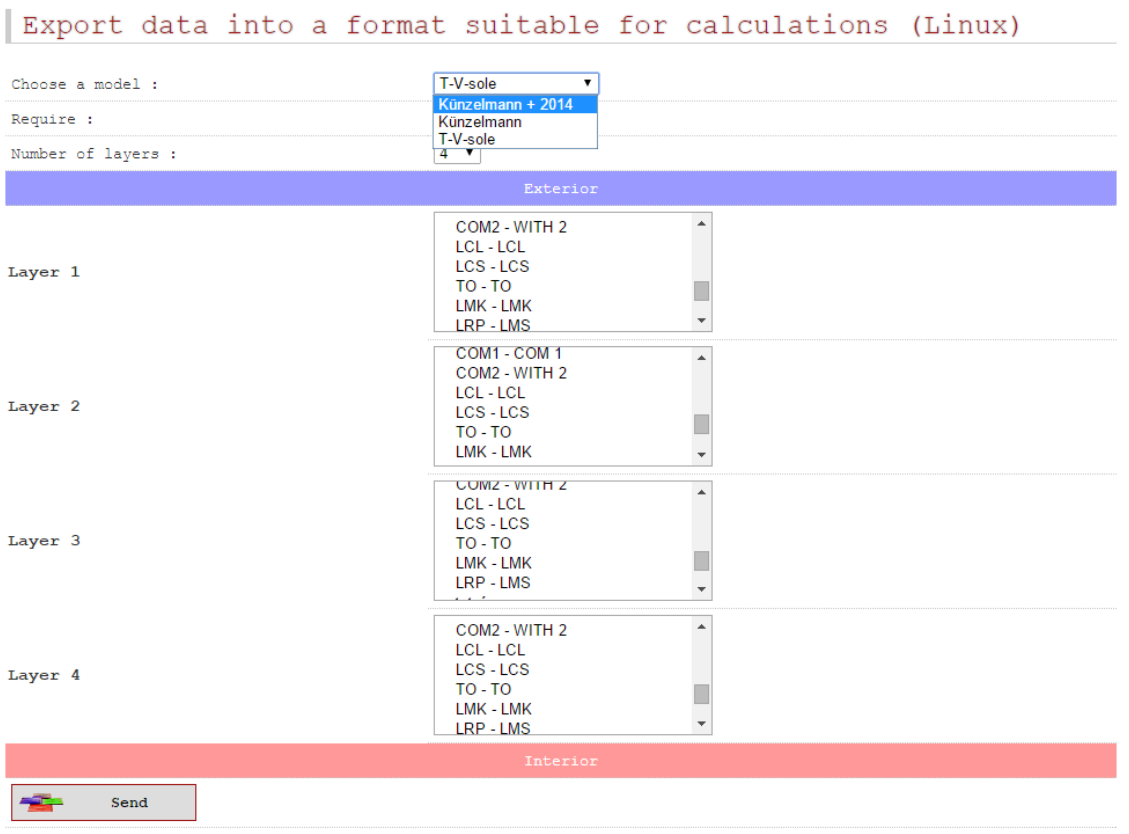

Figure 6: Export from the material database into a various formats.

\section{Example of computation}

A simple 1D problem was solved to illustrate the export of values from the Material Database and consecutive import to the simulation tool. As an example, sandstone originated from the quarry Úpice was chosen as a load-bearing masonry and a commercial renovation render as a binder. The thickness of sandstone wall was $800 \mathrm{~mm}$ and of render $20 \mathrm{~mm}$. 1D coupled heat and moisture transport problem was then solved by using a modified Künzel's mathematical model [6] integrated in the finite element method computing software SIFEL [7].

Summary of material properties is given in Table 1 (for details see references $[8,9])$, where $\rho_{v}\left[\mathrm{~kg} / \mathrm{m}^{3}\right]$ is the bulk density, $\psi[-]$ the porosity, $c[\mathrm{~J} / \mathrm{kgK}]$ the specific heat capacity, $\mu_{\text {dry cup }}[-]$ the water vapor diffusion resistance factor in dry conditions, $\mu_{\text {wet }}$ cup $[-]$ the water vapor diffusion resistance factor in wet conditions, $\lambda_{d r y}[\mathrm{~W} / \mathrm{mK}]$ the thermal conductivity in dry conditions, $\lambda_{\text {sat }}[\mathrm{W} / \mathrm{mK}]$ the thermal conductivity in water saturated conditions and $\kappa_{a p p}\left[\mathrm{~m}^{2} / \mathrm{s}\right]$ the apparent moisture diffusivity.

The interior boundary conditions were set to $21^{\circ} \mathrm{C}$ and $55 \%$ relative humidity. The boundary conditions on the exterior side were defined using the Test Reference Year (TRY) for Prague-Karlov. Prague (the Czech Republic) is a typical location with favorable weather conditions in Central Europe. The weather data used for calculation were obtained from CHMI and stored in the Weather Database [10]. 
354 Structural Studies, Repairs and Maintenance of Heritage Architecture XIV

Table 1: $\quad$ Basic material parameters of studied materials $[8,9]$.

\begin{tabular}{|c|c|c|}
\hline Parameter & $\begin{array}{c}\text { Sandstone } \\
\text { (SU) }\end{array}$ & $\begin{array}{c}\text { Renovation render } \\
\text { (SO1) }\end{array}$ \\
\hline$\rho_{v}\left[\mathrm{~kg} / \mathrm{m}^{3}\right]$ & 2433 & 1426 \\
\hline$\psi[\%]$ & 7.3 & 45.3 \\
\hline$c[\mathrm{~J} / \mathrm{kgK}]$ & 646 & 1083 \\
\hline$\mu_{\text {dry cup }}[-]$ & 76.9 & 27.09 \\
\hline$\mu_{\text {wet cup }}[-]$ & 11.32 & 9.25 \\
\hline$\lambda_{\text {dry }}[\mathrm{W} / \mathrm{mK}]$ & 3.665 & 0.532 \\
\hline$\lambda_{\text {sat }}[\mathrm{W} / \mathrm{mK}]$ & 4.167 & 1.165 \\
\hline$\kappa_{\text {app }}\left[\mathrm{m}^{2} / \mathrm{s}\right]$ & $1.12 \mathrm{E}-07$ & $3.68 \mathrm{E}-9$ \\
\hline
\end{tabular}

Examples of relative humidity and temperature fields in the wall undergoing a climatic load during a five-year period of simulated life cycle are presented in Figures 7-8.

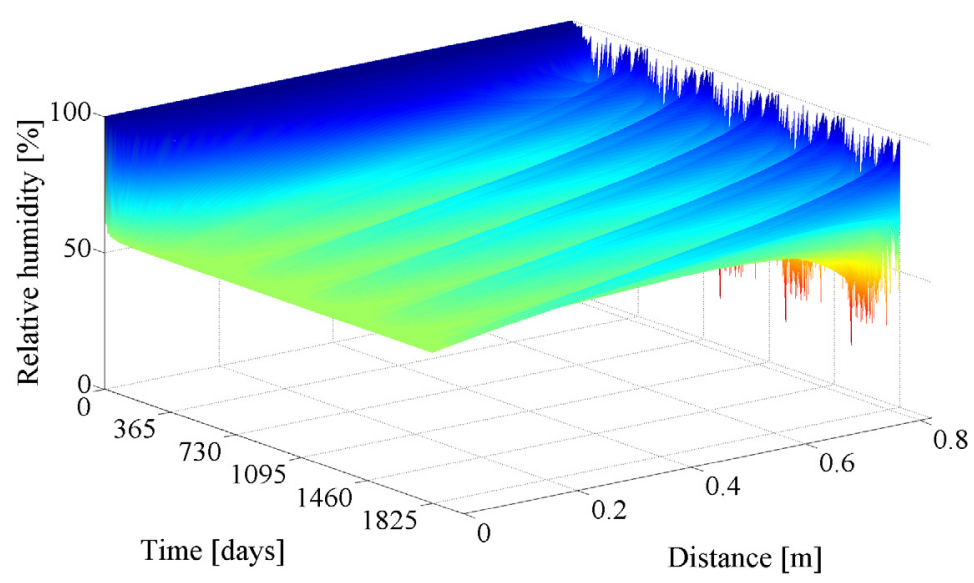

Figure 7: Relative humidity field in the tested sandstone wall. 


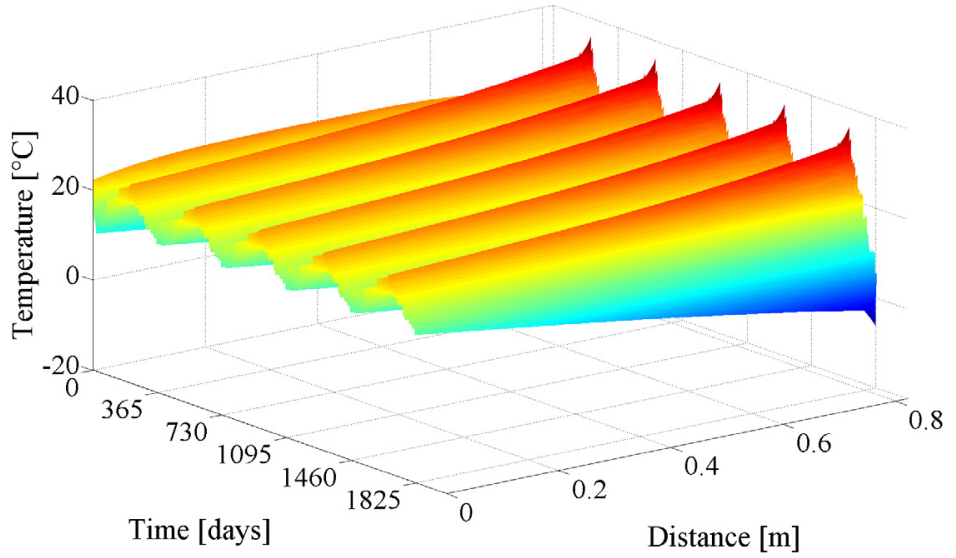

Figure 8: Temperature field in the tested sandstone wall.

\section{Conclusions}

The paper dealt with a data storage solution that improved and accelerated computer aided simulations of materials engineering issues at the Department of Materials Engineering and Chemistry, Faculty of Civil Engineering, CTU Prague. The solution consisted of a database layer based on MySQL relational database and application layer based on Nette PHP framework. Database operator interacted with the application by a system of html views generated by Nette framework. Data stored in the database system were then used by a simulation tool to predict hygrothermal behavior of a historical wall in five-year period. Screenshots with respect to data manipulation between the database and the external simulation tool together with an example demonstrating the simulation output were presented as well.

\section{Acknowledgement}

This research has been supported by the Ministry of Culture of the Czech Republic, under project No DF12P01OVV030.

\section{References}

[1] Martin, P., Haefeli, W. E., Martin-Facklam, M., A Drug Database Model as a Central Element for Computer-Supported Dose Adjustment within a CPOE System. Journal of the American Medical Informatics Association, vol. 5, pp. 427-432, 2004.

[2] Sluiter, M. H. F., Simonovic, D., Tasci, E. S., Materials databases for the computational materials scientist. International journal of minerals metallurgy and materials, vol. 18, issue: 3, pp. 303-308, 2011. 
[3] Gidding, A., Levy, T. E., DeFanti, T. A., ARCHAEOSTOR: The Development and Utilization of a Web-based Database for the Field and Lab, Near Eastern Archaeology, vol. 77, issue: 3, pp. 198-202, 2014.

[4] Kiselyova N. N., Prokoshev, I. V., Dudarev, V. A., Khorbenko, V. V., Belokurova, I. N., Podbel'skii, V.V., Zemskov, V. S., Internet-accessible electronic materials database system. Inorganic materials, vol. 40, issue: 3, pp. 321-325, 2004.

[5] Ozao R., Sawaguchi, T., Ishida, H., Iji, M., Furuyama, T., Shinohara, Y., Yamada, K., Halada, K., Eco-MCPS: a newly developed web-based database for eco-materials in Japan. Materials transactions, vol. 48, issue 12, pp. 3043-3049, 2007.

[6] Ďurana, K., Kočí, J., Maděra, J., Pokorný, J., Černý, R., Modification of the computational model of coupled heat and moisture transport: the transition between the liquid and gaseous phases of water. AIP Conference Proceedings, 2014, in press.

[7] Kruis, J., Koudelka, T., Krejčí, T., Efficient computer implementation of coupled hydro-thermo-mechanical analysis. Mathematics and Computers in Simulation, 80, pp. 1578-1588, 2010.

[8] Korecký, T., Jerman, M., Černý, R., The moisture diffusivity coefficient of different types of sandstone, Stavebni obzor [online], 23 (1-2), pp. 16-19, 2014.

[9] Vejmelková, E., Máca, P., Keppert, M., Rovnaníková, P., Černý, R., Commercial renovation renders: mechanical, hygric, thermal and durability properties. Cement Wapno Beton, 16/78, no. 5, pp. 288-298, 2011.

[10] Ďurana, K., Maděra, J., Černý, R., Database of climatic data as a rewarding tool for inclusion of weather observations in computational service life assessments of historical buildings. WIT Transactions on the Built Environment, 131, pp. 245-256, 2013. 